\title{
EFICIÊNCIA DE TESTES COLORIMÉTRICOS PARA DETERMINAÇÃO DA VIABILIDADE DO PÓLEN EM ACESSOS DE FEIJÃO-FAVA (Phaseolus lunatus L)
}

Letícia da Guia Alves de Jesus ${ }^{1}$, Liliann Ribeiro Tavares ${ }^{1}$, Maria Fernanda da Costa Gomes², Sérgio Emílio dos Santos Valente ${ }^{3}$, Regina Lucia Ferreira Gomes ${ }^{4}$, Angela Celis de Almeida Lopes ${ }^{4}$, Marcones Ferreira

Costa $^{1 *}$

\begin{abstract}
RESUMO - O feijão-fava (Phaseolus lunatus L.) é uma importante fonte de alimento para o Brasil principalmente para a região Nordeste. Devido à relevância dessa leguminosa, estudos em melhoramento genético se fazem necessários, sendo que informações sobre a viabilidade polínica constitui um dos fatores responsáveis pelo sucesso dos programas de melhoramento via hibridação. Com o intuito de fornecer informações a respeito dos acessos de feijão-fava provenientes do Banco Ativo de Germoplasma da Universidade Federal do Piauí (BAG-UFPI), objetivou-se estimar a viabilidade polínica de nove acessos, através de quatro métodos coloriméticos: carmim acético $2 \%$, orceína acética $2 \%$, fucsina e lugol. Foram coletados os botões florais na pré-antese e fixados em etanol:ácido acético (3:1) por 24 horas e, posteriormente, permaneceram em etanol $70 \%$ sob refrigeração até a preparação das lâminas pela técnica de esmagamento. Foi utilizado um delineamento inteiramente casualizado em esquema fatorial e os dados foram comparados pelo teste Scott-Knott ao nível de 5\% de probabilidade de erro. Os quatro métodos colorimétricos foram eficientes em estimar a viabilidade entre os acessos, os quais apresentaram alta viabilidade polínica com valores acima de 70\%, importante para viabilização dos trabalhos de melhoramento genético.
\end{abstract}

Palavras chave: banco de germoplasma, carmim acético, cruzamentos genéticos, orceína acética.

\section{EFICIENCY OF COLORIMETRIC TESTS FOR DETERMINATION OF VIABILITY OF POLLEN IN ACCESS OF LIMA BEAN (Phaseolus lunatus L)}

\begin{abstract}
One of the principal limitations for the application of a system of direct planting in organic agriculture is the management of cover crops, because of the inability to use herbicides for desiccation of vegetation. The objective of this work was to evaluate diverse forms of management of plant material and planters, on different cover crops, for an organic system of production. Six types of machines and implements for mowing and crushing of plants and three types of planters were evaluated. It was verified that the tractor knife roller and the microtractor were the best options, standing out with greater operational efficiency and lower costs for labor, as well as providing good levels of soil cover. A planter of 2 rows was more efficient than the others, as well as being of potential use in direct planting in bigger areas. In small areas of family farmers, the use of a jab planter is a good option, whereas the 1 row planter did not present a return of work that justified its use in direct planting in plant litter.
\end{abstract}

Keywords: agroecology, soil conservation, organic crop, planters.

\footnotetext{
${ }^{1}$ Universidade Federal do Piauí, Campus Amílcar Ferreira Sobral, BR 343, km 3,5 - Bairro Meladão, Floriano, PI, Brasil, 64808-605. *Autor para correspondência: marconescosta@ufpi.edu.br

${ }^{2}$ Universidade Federal do Piauí, Programa de Pós-Graduação em Genética e Melhoramento, Campus Socopo, Teresina, PI, Brasil, 64049-550.

${ }^{3}$ Universidade Federal do Piauí, Centro de Ciências da Natureza, Departamento de Biologia, Campus Ininga, Teresina, PI, Brasil, 64049-550.

${ }^{4}$ Universidade Federal do Piauí, Departamento de Fitotecnia, Centro de Ciências Agrárias, Teresina, PI, Brasil, 64049-550.
} 


\section{INTRODUÇÃO}

O gênero Phaseolus compreende cinco espécies domesticadas ( $P$. vulgaris, $P$. lunatus, $P$. coccineus, $P$. accutifolius e $P$. plianthus), sendo que a espécie Phaseolus lunatus, conhecida por feijão-fava ou feijãolima é a segunda leguminosa de maior importância do gênero, sendo composta por duas variedades botânicas: $P$. lunatus var. silvester Baudet e P. lunatus var. lunatus (Baudet, 1977).

O feijão-fava caracteriza-se por ser uma planta herbácea com ciclo de vida anual curto (Webster et al., 1979) e germinação epígena, que acontece usualmente entre seis e dez dias após a semeadura, pode apresentar hábito de crescimento determinado ou indeterminado. O hábito de crescimento determinado é caraterizado pelo desenvolvimento total da gema apical em uma inflorescência e o indeterminado é caraterizado pelo desenvolvimento da gema terminal em uma guia (Oliveira et al., 2015; Zimmermann \& Teixeira, 1996).

As análises morfológicas, bioquímicas e moleculares indicam que existem três principais pools genético para a espécie: o Andino, Mesoamericano I e o Mesoamericano II, sendo que em cada grupo apresenta formas selvagens e domesticadas (Serrano-Serrano et al., 2012; MartínezCastillo et al., 2014; Camacho-Pérez et al., 2017). Estudos em diversas regiões do Brasil tem revelado um elevado número de variedades morfológicas, sugerindo que a diversidade genética no Brasil pode ser tão alta quanto à relatada para a Penísula de Yucatán, centro de diversidade genética para essa cultura (Martínez-Castillo et al., 2012; Penha et al., 2016; Silva et al., 2017).

O feijão-fava apresenta elevada diversidade genética, o que permite um alto potencial de produção e adaptação a diferentes condições climáticas, chegando a ser considerada tolerante à seca, ao excesso de umidade e ao calor (Vieira, 1992; Long et al., 2014). È uma cultura importante para a região Nordeste do Brasil, pois se destaca como uma espécie de subsistência, sendo produzida em regime de sequeiro, principalmente por parte do setor da agricultura familiar (Lopes et al., 2015; Silva et al., 2015).

Nota-se a relevância da cultura de feijão-fava, sendo que estudos em melhoramento genético para essa leguminosa são essenciais, uma vez que irão oferecer informações agronomicamente importantes. Desse modo a viabilidade polínica é um dos fatores responsáveis pela escolha de grãos de pólen viáveis que influenciam no sucesso dos cruzamentos e também a seleção de genótipos que são utilizados em programas de melhoramento genético (Cabral et al., 2013).

A viabilidade polínica pode ser determinada por um grande número de técnicas: métodos diretos, como a indução da germinação do pólen in vivo ou in vitro ou pelos métodos indiretos, que são baseados em parâmetros citológicos, como os testes colorimétricos (Oliveira et al., 2001). Segundo Hister \& Tedesco (2016), é importante testar vários tipos de corantes, com o intuito de encontrar o mais apropriado para cada espécie estudada, pois não há na literatura um teste geral de viabilidade que utiliza apenas um determinado corante.

Diante disto temos por finalidade estimar a viabilidade polínica de nove acessos de feijão-fava, do Banco Ativo de Germoplasma da Universidade Federal do Piauí (BAG-UFPI) através de distintos métodos colorimétricos, com o intuito de indicar genótipos férteis, com potencial para serem utilizados em programas de melhoramento genético, via hibridação.

\section{MATERIALE MÉTODOS}

O material botânico constitui nove acessos do Banco Ativo de Germoplasma de feijão-fava da Universidade Federal do Piauí (BAG-UFPI), a saber, UFPI- 948, UFPI-948, UFPI- 956, UFPI- 961, UFPI-964, UFPI- 965, UFPI- 1000, UFPI-1002, UFPI-1016. Durante o período de floração, botões florais em estádio de pré-antese foram coletados e fixados em solução de etanol: ácido acético (3:1) por 24h. Em seguida, foram transferidos para uma solução de álcool $70 \%$ e conservados por refrigeração até serem utilizados.

O estudo compreende uma análise quantitativa, no qual as lâminas contendo os grãos de pólen foram preparadas segundo a técnica de esmagamento das anteras descrita por Guerra \& Souza (2002). Foram utilizados quatro métodos colorímetros distintos, a orceína acética $2 \%$, o carmim acético $2 \%$, lugol e fucsina, que possibilitaram, além de estimar a viabilidade polínica, determinar o corante mais eficiente para a técnica na espécie em estudo. Sob as lâminas contendo pólens, foi depositada uma gota do corante e posteriormente visualizada no microscópio, em objetiva com aumento de 40X.

O delineamento utilizado para o teste colorimétrico foi inteiramente casualizado em esquema fatorial nove 
x quatro (acessos x corantes), sendo preparadas três lâminas para cada corante e avaliando 500 grãos de pólen por lâmina, totalizando 1500 pólens por teste e 6000 por acesso. Os dados foram submetidos à análise da variância (ANOVA) e comparados pelo teste ScottKnott ao nível de 5\% de probabilidade de erro, com o auxílio do programa estatístico Assistat ${ }^{\circledR}$, versão beta 7.7 (Silva, 2016).

\section{RESULTADOS E DISCUSSÃO}

Os quatros corantes utilizados foram capazes de distinguir os pólens viáveis dos inviáveis em feijãofava, como mostra a Figura 1. Para o carmim acético (Figura 1A) pode-se observar que os grãos de pólens viáveis apresentaram coloração avermelhada e os inviáveis como indicados pelas setas, apresentaram tamanho reduzido e sem coloração. Segundo Pagliarini \& Pozzobon (2004), isso acontece devido uma relação de afinidade que existe com o carmim ao entrar em contato com DNA e RNA dos pólens viáveis.

Os grãos de pólen corados com fucsina (Figura 1B) mostram os pólens inviáveis com um tamanho reduzido em relação aos viáveis. Quando tratados com orceína acética $2 \%$, os pólens inviáveis como indicado pelas setas apresentaram tamanho reduzido, com uma coloração mais clara em comparação com os viáveis (Figura B). Enquanto, os grãos de pólen inviáveis tratados com lugol (Figura 1D) apresentaram uma coloração amarela clara, devido a ausência de amido no pólen, enquanto os viáveis mostraram uma coloração marrom escuro, que é o resultado da reação do amido presente no pólen com o iodo da solução.

Foi possível observar a existência de variação significativa entre a porcentagem de pólens viáveis, que é consequência da existência de variabilidade genética entre os distintos acessos. De acordo com Zanotto et al. (2009), a viabilidade do grão de pólen pode apresentar uma grande variação dentro de uma mesma espécie com variedades distintas. Os resultados obtidos mostraram porcentagens dos grãos de pólen viáveis acima de $70 \%$ para os quatros tipos de corantes (Tabela 1). Valores de viabilidade polínica acima de $70 \%$ são classificados como altos e também adequados para serem usados em programas de melhoramento de plantas. (Souza et al., 2002).

Quando comparadas as médias dos acessos entre os corantes, foram encontradas diferenças significativas para todos os acessos analisados, com exceção do acesso UFPI- 948 (Tabela 1). As diferenças significativas encontradas supostamente estão relacionadas com a afinidade do corante com a exina e a intina do grão de pólen, como pode ser observado no acesso UFPI961 , em que os corantes carmim acético $2 \%$, lugol e fucsina indicaram uma viabilidade superior a $90 \%$ e enquanto a orceína acética $2 \%$ indicou uma porcentagem inferior a $75 \%$.

Os acessos UFPI- 628 e UFPI- 956 apresentaram diferenças significativas entre a fucsina e os demais métodos de coloração, sendo que a maior média de viabilidade para esses acessos foi estimada por esse corante. Os acessos UFPI- 961, UFPI- 965, UFPI- 1000 apontaram diferenças significativas quando corados com orceína acética a $2 \%$, sendo que os valores médios de viabilidades apresentados por esse corante foram os mais baixos, entretanto os referidos acessos ainda apresentam uma alta taxa de grãos de pólen viáveis. Já para os acessos UFPI- 1002 e UFPI-1016 a diferença significativa ocorreu entre o lugol e os demais corantes, sendo que esses acessos apresentaram as menores médias quando corados com lugol. Quanto maior for a viabilidade polínica, maiores serão as chances de formação de associações entre alelos, que consequentemente ocasionará o aumento da variabilidade genética.

Ao serem comparadas as porcentagens médias entre os acessos dentro de cada corante, foram encontradas diferenças significativas de viabilidade polínica nos mesmos, com exceção do corante fucsina que apresentou as maiores médias de grãos de pólen viáveis para todos os acessos (<90\%), entretanto pode ter acontecido à superestimação da viabilidade polínica para esse corante, devido à dificuldade de distinção entre os grãos de pólen viáveis e não viáveis (Tabela 1).

Os indivíduos de uma mesma espécie podem apresentar diferenças significativas com relação à viabilidade polínica e isso pode estar relacionado a fatores abióticos. Alteração moderada da temperatura pode reduzir o número de pólens e sua viabilidade podendo gerar problemas durante a fertilização. Em casos mais graves, pode resultar na completa esterilidade do grão de pólen ou inibição da deiscência das anteras e, consequentemente, nenhuma frutificação (Hedhly, 2011). 


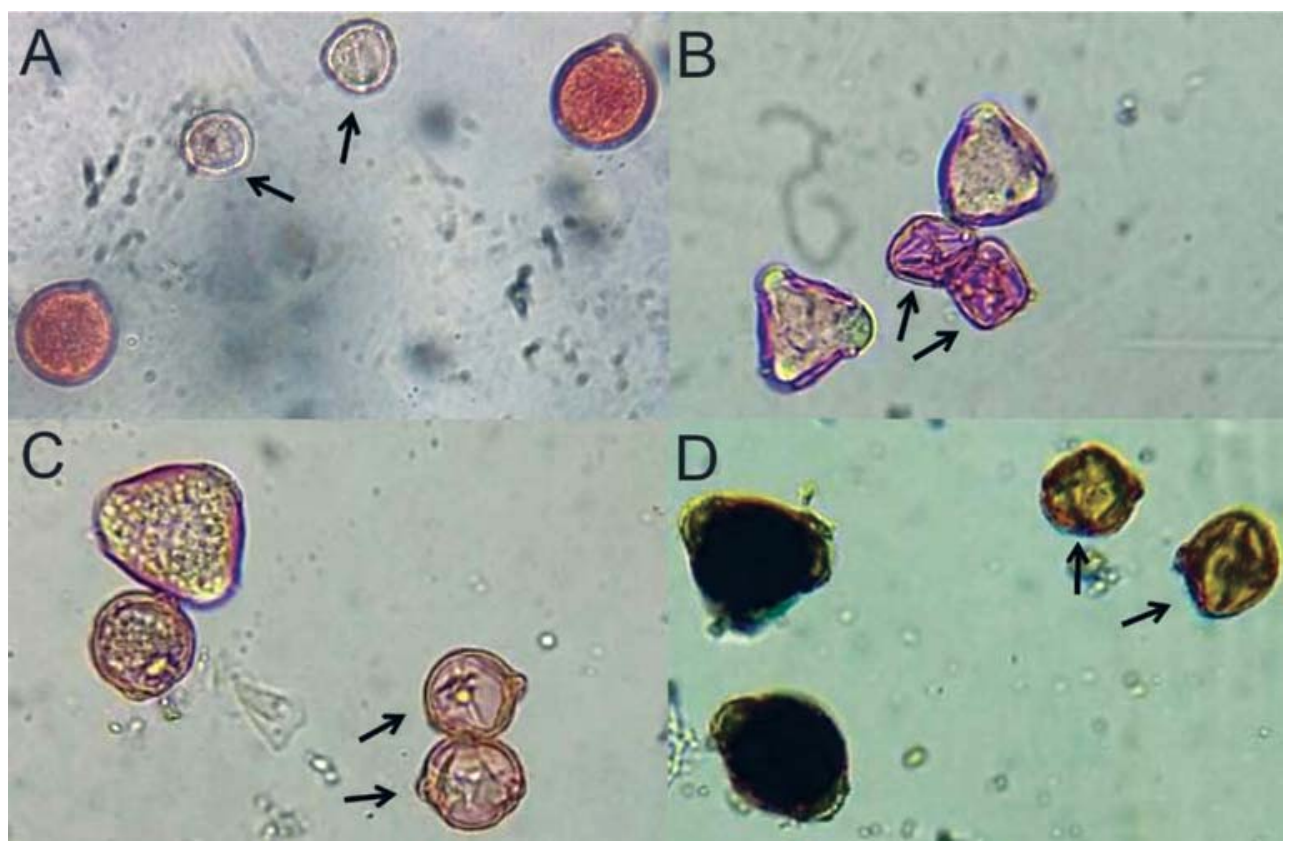

Figura 1- Grãos de pólen submetidos a diferentes métodos de coloração. A: carmim acético 2\%; B: orceína acética 2\%; C: lugol; D: fucsina básica. Setas indicam grãos de pólen inviáveis.

Tabela 1 - Valores médios referentes à viabilidade polínica de acessos de feijão-fava do BAG-UFPI, para os quatro métodos colorimétricos utilizados, dados em porcentagem (\%)

\begin{tabular}{lcccc}
\hline Acessos & Carmim acético 2\% & Orceína acética $2 \%$ & Lugol & Fucsina \\
\hline UFPI-628 & $77,19 \mathrm{bB}$ & $82,58 \mathrm{bB}$ & $86,19 \mathrm{bB}$ & $95,23 \mathrm{aA}$ \\
UFPI-948 & $86,97 \mathrm{aA}$ & $90,20 \mathrm{aA}$ & $93,30 \mathrm{aA}$ & $98.03 \mathrm{aA}$ \\
UFPI-956 & $79,69 \mathrm{bB}$ & $74,31 \mathrm{cB}$ & $77,64 \mathrm{bB}$ & $94,30 \mathrm{aA}$ \\
UFPI-961 & $95,63 \mathrm{aA}$ & $74,87 \mathrm{cB}$ & $93,67 \mathrm{aA}$ & $91,67 \mathrm{aA}$ \\
UFPI-964 & $87,67 \mathrm{aB}$ & $80,47 \mathrm{bB}$ & $94,53 \mathrm{aA}$ & $93,60 \mathrm{aA}$ \\
UFPI-965 & $95,14 \mathrm{aA}$ & $85,48 \mathrm{bB}$ & $97,20 \mathrm{aA}$ & $93,40 \mathrm{aA}$ \\
UFPI-1000 & $89,92 \mathrm{aA}$ & $82,53 \mathrm{bB}$ & $93,73 \mathrm{aA}$ & $91,27 \mathrm{aA}$ \\
UFPI-1002 & $95,50 \mathrm{aA}$ & $95,07 \mathrm{aA}$ & $86,93 \mathrm{bB}$ & 96,60 aA \\
UFPI-1016 & $90,567 \mathrm{aA}$ & $93,73 \mathrm{aA}$ & $83,27 \mathrm{bB}$ & 95,37 aA \\
\hline
\end{tabular}

Letras maiúsculas diferentes nas linhas correspondem às diferenças dentro dos acessos, entre os corantes. Letras minúsculas diferentes nas colunas correspondem às diferenças entre os corantes, para cada acesso. * Médias seguidas pela mesma letra maiúscula na linha e minúscula na coluna não diferem estatisticamente entre si, pelo Teste de Scott-Knott ao nível de 5\% de probabilidade de erro.

De modo geral, os testes colorimétricos apresentam vantagens no estudo da viabilidade do pólen, uma vez que são métodos rápidos, baratos e seguros, auxiliam na análise dos fatores ambientais que afetam o desenvolvimento polínico, na identificação de possível macho- esterilidade e no restabelecimento de linhagens e na determinação do período ótimo da polinização de uma espécie.

\section{CONCLUSÃO}

A utilização das soluções histoquímicas avaliadas neste experimento foram capazes de distinguir os pólens viáveis dos inviáveis. Os quatro testes colorimétricos analisados foram eficientes na estimativa da viabilidade e indicaram altas taxas de viabilidade do grão de pólen. Dos nove acessos de pimentas avaliados do BAG- 
UFPI todos apresentaram alta viabilidade polínica (<70\%), fator de extrema importância para caracterização desses recursos genéticos e viabilização dos trabalhos de melhoramento genético, sendo que os mesmos possuem potencial para serem utilizados nos cruzamentos genéticos.

\section{LITERATURACITADA}

BAUDET, J.C. The taxonomic status of the cultivated types of Lima bean (Phaseolus lunatus L.). Trop Grain Legume, n.7, p.29-30, 1977.

CABRAL, J.C.; ROSSI, A.A.B.; KLEIN, M.E. et al. Estimativa da viabilidade polínica em acessos de Theobroma cacao L. baseada em testes calorimétricos. Enciclopédia Biosfera, v.9, n.17, p.2780-2788, 2013.

CAMACHO-PÉREZ, L.; MARTÍNEZ-CASTILLO, J.; MIJANGOS-CORTÉS, J. O. et al. Genetic structure of Lima bean (Phaseolus lunatus L.) landraces grown in the Mayan area. Genetic Resources and Crop Evolution, p.1-13, 2017. DOI 10.1007/s10722-017-0525-1.

GUERRA, M.; SOUZA, M.J. Como observar cromossomos: um guia de técnicas em citogenética vegetal, animal e humana. Ribeirão Preto, SP: FUNPEC, 2002. 131p.

HEDHLY, A. Sensitivity of flowering plant gametophytes to temperature fluctuations. Environmental and Experimental Botany, England, v.74, p.9-16, 2011.

HISTER, C.A.L.; TEDESCO, S.B. “Estimativa da viabilidade polínica de araçazeiro (Psidium cattleianum Sabine) através de distintos métodos de coloração." Revista brasileira de plantas medicinais, v.18, n.1, p.135-141, 2016.

LONG, R.; TEMPLES, S.; MEYER, R. et al. Lima Bean Production in California.

University of California, ANR, n.8505, p.25, 2014.

LOPES, Â.C.A.; VALENTE, S.E.; GOMES, R.L.F. et al. Morphological Characterization and Study of Genetic Diversity in Lima Bean Accessions. In: FERREIRA, A.S.; LOPES, A.C.A.; GOMES, R.L. Phaseolus lunatus. Diversity, Growth and Production. 1.ed. New York: Nova Sicence Publishers, Inc., 2015. p.1-26.
MARTÍNEZ-CASTILLO, J.; CAMACHO-PÉREZ, L.; COELLO-COELLO, J. et al. Wholesale replacement of Lima bean (Phaseolus lunatus L.) landraces over the last 30 years in northeastern Campeche, Mexico. Genetic resources and crop evolution, v.59, n.2, p.191-204, 2012.

MARTÍNEZ-CASTILLO, J.; CAMACHO-PÉREZ, L.; VILLANUEVA-VIRAMONTES, S. et al. Genetic structure within the Mesoamerican gene pool of wild Phaseolus lunatus (Fabaceae) from Mexico as revealed by microsatellite markers: implications for conservation and the domestication of the species. American Journal of Botany, v.101, n.5, p.851-864, 2014.

OLIVEIRA, M.S.P.; MAUÉS, M.M.; KALUME, M.A.A. Viabilidade de pólen in vivo e in vitro em genótipos de açaizeiro. Acta Botânica Brasílica, v.15, n.1, p.27-33, 2011.

OLIVEIRA, M.C.P.; MEIRELLES, A.C.S.; LOPES, A.C.A. et al. Phenology, vegetative development and pollen viability. Accessions. In: FERREIRA, A.S.; LOPES, A.C.A.; GOMES, R.L. (Eds.).

Phaseolus lunatus. Diversity, Growth and Production. 1.ed. New York: Nova Sicence publishers, Inc., 2015. p.1-26.

PAGLIARINI, M.S.; POZZOBON, M.T. II Curso de citogenética aplicada a recursos genéticos vegetais. Brasília, DF: Embrapa Recursos Genéticos e Biotecnologia, 2004.

PENHA, J.S.; LOPES, A.C.A.; GOMES, R.L.F. et al. Estimation of natural outcrossing rate and genetic diversity in Lima bean (Phaseolus lunatus L. var. lunatus) from Brazil using SSR markers: implications for conservation and breeding. Genetic Resources and Crop Evolution, p.1-10, 2016.

SOUZA, M.M.; PEREIRA, T.N.S.; MARTINS, E.R. Microsporogênese e microgametogênese associadas ao tamanho do botão floral e da antera e viabilidade polínica em maracujazeiro-amarelo (Passiflora edulis Sims f. flavicarpa Degener). Ciência e Agrotecnologia, v.26, n.6, p.1209-1217, 2002.

SERRANO-SERRANO, M.L.; ANDUEZA-NOH, R.H.; MARTÍNEZ-CASTILLO, J. et al. Evolution and domestication of lima bean in Mexico: Evidence from ribosomal DNA. Crop Science, v.52, n.4, p.1698-1712, 2012. 
SILVA, FAS. ASSISTAT. Versão 7.7 beta. DEAGCTRN-UFCG. Atualizado em 04 de janeiro de 2016. Disponível em $<$ http://www.assistat.com/>. (Acessado em: 24 de fevereiro de 2017)

BRITO DA SILVA, V.; GOMES, R.L.F.; LOPES, A.C.A. et al. Genetic diversity and promising crosses indication in Lima bean (Phaseolus lunatus) accessions. Semina: Ciências Agrárias, v.36, n.2, 2015.

SILVA, R.N.O.; BURLE, M.L.; PÁDUA, J.G. et al. Phenotypic diversity in lima bean landraces cultivated in Brazil, using the Ward-MLM strategy. Chilean Journal of

Agricultural Research, v.77, n.1, p.35, 2017.

VIEIRA, R.F. A cultura de feijão-fava. Informe Agropecuário, v.16. n.174, p.30-37,1992.
WEBSTER, B.D.; TUCKER, C.L.; LYNCH, S.P. A morphological study of the development of reproductive structures of Phaseolus vulgaris L. Journal of the American Society for Horticultural Science, v.102, p.640-643, 1977.

ZIMMERMANN, M.J.O.; TEIXEIRA, M.G. Origem e evolução. In: ARAÚJO, R.S.; RAVA, C.A.; STONE, L.F. et al. Cultura do feijoeiro comum no Brasil. Piracicaba (BR): POTAFOS, 1996. p.57-70.

ZANOTTO, M.; BRAMMER, S.P.; NASCIMENTO JÚNIOR, A. et al. Viabilidade polínica como seleção assistida no programa de melhoramento genético de triticale. Ciência e Agrotecnologia, v.33, Edição Especial, p.20782082, 2009.

Recebido para publicação em 29/6/2017 e aprovado em 19/2/2018. 